\title{
Health-preserving environment subjects interaction technologies in primary school
}

\author{
Elena Bystritskaya, Elena Grigoryeva*, Maria Lebedkina, Ivan Sedov and Oleg Musin \\ Kozma Minin Nizhny Novgorod State Pedagogical University, 603005, Nizhny Novgorod, Russia
}

\begin{abstract}
There are no common approaches in health forming technologies classification for use in primary school. Thus, subjects of health-preserving technologies subjects cannot be determined, neither for designing and executing projects, nor for creating appropriate environment. There are different points of view in literature on duties on forming pupils of primary school of these subjects and directions of interactions are barely viewed at best. The goal of this article is to classify technologies used in health-preserving environment for primary school, based on subjects of designing and executing of these projects and to create a technology system of health-preserving technology subjects' interaction for the benefit of primary school students ternary health harmonious development. Basic research methods are comparative analysis and pedagogical modelling of educational process subjects' interaction system in the field of forming health-preserving environment in primary schools for the sake of juveniles' physical, psychical and social health complex development. The result is classification of healthpreserving technologies on their designing and executing subjects and their interaction technology within their functional duties in primary school pupils' sanitation. This article can be useful for primary school pupils' parents and primary school teachers for their non-conflict interactions for sake of 1-4 grade pupils health preserving. In addition, it can help to create health caring environment in school, family and additional learning facilities. Also this article can be helpful to specialists in additional educational system. It's goal, among the others, is to prepare health preserving technologies project specialists.
\end{abstract}

\section{Introduction}

General statement of the problem and its connection with important scientific and practical tasks. The problem of classification and description of modern health-forming technologies from position of objects' and subjects 'activity is very relevant due to large number of innovative techniques and methods are appearing. These are, according to authors, related to heath forming [1-3]. Interactions of parents and teachers, based on scientifically sound information, can help to solve this problem and promote adequate using of health-forming technologies $[4,5]$.

The relevance of this research is in theoretically and practically approved necessity of all subjects target interaction providing analysis, correction, technological supply,

\footnotetext{
*Corresponding author: gvelnn@mail.ru
} 
substantial direction and realization of health-forming technologies for use on primary school students.

There are great number of heath-forming technologies descriptions researches, but they are primarily concentrated on physical heath and some elements of psychical health $[6,7]$. There are other researches, based on social activity and social role of primary school student $[8,9]$. But there are very few researches, where all health components are presented as a single object and result of using specific integrated health-forming technology.

Thus, the problem of research is contradiction between necessity of health-forming subjects' activity harmonization in primary school and low validity and practical realization of techniques, reducing this contradiction.

The goal of the article is to make a classification of health-forming technologies usable in primary school, description of approved system of interaction for subjects of healthforming technologies using actualized techniques.

Authors discovered that there is no health-forming technologies classification on subject's and object's activity. As a rule, same methods and technologies are used for different social and age groups with minor adaptation to subjects' physical condition and situation. Thus, author had the goals to divide current health-forming technologies by activity subjects and to determine the features of objects of activity according to subjects' features. Also the goal is to determine structure and measurements for interactions as it required for educational technologies.

\section{Materials and methods}

\section{Methods and technologies used in research}

For example, comparative analysis of literature sources allowed revealing characteristics of process and results of using complex of health and medical events for correction of somatic health disorders.

In addition, it became possible to determine the way of influence of different types of educational activity of subject's organism and behavior. Primary school pupils were selected as a subject of health-forming technologies. Different types of technology was viewed in order to select the most effective ones for different components of child's health.

Pedagogical modelling was used for developing authors' classification of healthforming technologies by subject and object of impact and technology of subject's primary school pupils' health-forming activity.

Ascertaining diagnostic of different methods and techniques of health forming and results of their use in primary school was held during the experimental research. An educational processes subjects interaction technology was implemented during a formative experiment. These subjects were also congruent health forming process's subjects.

\section{Results and discussion}

\section{Main research material with full rationale.}

During theoretical research and formative experiment authors revealed primary school pupils' health-forming process's subjects. At the same time, during ascertaining study their participation weight was determined. The results are in Table 1.

Table 1. Educational process subjects' participation in primary school pupils health forming

\begin{tabular}{|l|c|c|c|}
\hline $\begin{array}{c}\text { Health-forming } \\
\text { subject }\end{array}$ & $\begin{array}{c}\text { Particip } \\
\text { ation } \\
\text { weight }\end{array}$ & $\begin{array}{c}\text { Technology and } \\
\text { it's result }\end{array}$ & Subject and object of interaction \\
\hline Classmates & $18 \%$ & Motivational & Cooperative activity of friendly type, \\
\hline
\end{tabular}




\begin{tabular}{|c|c|c|c|}
\hline & & $\begin{array}{l}\text { activity } \\
\text { technologies }\end{array}$ & $\begin{array}{l}\text { competitive type, } \\
\text { reflective type, less comparative } \\
\text { mentor type }\end{array}$ \\
\hline Sports team & $9 \%$ & $\begin{array}{l}\text { Competitive activity } \\
\text { technologies }\end{array}$ & $\begin{array}{l}\text { Cooperative activity of competitive } \\
\text { type, comparative reflective type. }\end{array}$ \\
\hline $\begin{array}{l}\text { Family (parents or } \\
\text { older generations) }\end{array}$ & $38 \%$ & $\begin{array}{l}\text { Wellness and } \\
\text { leisure, technologies } \\
\text { for the formation of } \\
\text { a health culture }\end{array}$ & $\begin{array}{l}\text { Dependable (executive) activity and } \\
\text { interaction at a high level of } \\
\text { emotionality (attachment, } \\
\text { relationships, stable feelings). }\end{array}$ \\
\hline $\begin{array}{ll}\text { Same } & \text { generation } \\
\text { relatives } & \end{array}$ & $12 \%$ & $\begin{array}{l}\text { Socially } \\
\text { authoritative } \\
\text { technologies }\end{array}$ & $\begin{array}{l}\text { Emotional attachment against the } \\
\text { background of actual competition, } \\
\text { parity interaction, partly mentoring, } \\
\text { caring. }\end{array}$ \\
\hline $\begin{array}{l}\text { Temporary children's } \\
\text { groups (children's } \\
\text { health camp, a group } \\
\text { of friends in the local } \\
\text { area, a community) }\end{array}$ & $8 \%$ & $\begin{array}{l}\text { The technology of } \\
\text { using the healing } \\
\text { forces of nature }\end{array}$ & $\begin{array}{l}\text { Situational interaction, in a situation } \\
\text { of survival problems and security } \\
\text { threats (physical, psychological, } \\
\text { personal and social). }\end{array}$ \\
\hline Teachers & $7 \%$ & $\begin{array}{l}\text { Technologies for } \\
\text { the formation of a } \\
\text { health culture, } \\
\text { health-preserving } \\
\text { technology }\end{array}$ & $\begin{array}{l}\text { Leveled interaction, transfer of } \\
\text { experience from senior to junior, } \\
\text { authoritative interaction, the } \\
\text { formation of self-regulation and self- } \\
\text { control. }\end{array}$ \\
\hline $\begin{array}{l}\text { Physical education } \\
\text { teacher }\end{array}$ & $5 \%$ & $\begin{array}{l}\text { Health preserving } \\
\text { technology and } \\
\text { correction of } \\
\text { ternary-component } \\
\text { health }\end{array}$ & $\begin{array}{l}\text { Authoritative interaction based on } \\
\text { emotionally attractive activities, } \\
\text { cooperation, mutual support based on } \\
\text { informal leadership. }\end{array}$ \\
\hline Coach & $3 \%$ & $\begin{array}{l}\text { Corrective- } \\
\text { developing } \\
\text { technologies }\end{array}$ & $\begin{array}{l}\text { Directive authoritarian interaction, } \\
\text { mastering the principles and rules of } \\
\text { self-control and self-realization of } \\
\text { the feeling of an internal coach. }\end{array}$ \\
\hline
\end{tabular}

Primary school pupils' health-forming technologies classification must have two grounds: 1) subject of impact on child and his health-forming process; 2) activity object which presumes unique independent result. Assuming that first subject of the impact is always primary school pupil, we determine second subject and object as a classification parameter. Authors' classification of health-forming technologies for primary school pupils is following:

1. Subject - children's team, object - social cooperation, technology - the formation of a health culture;

2. Subject - family, object - preservation and correction of health, technology correctional development;

3. Subject - teaching staff, object - preservation and replenishment of health, technology - health preservation and the formation of a health culture;

4. Subject - physical education teachers, object - correction of all health components, technology - problem training and education;

5. Subject - the child himself, object - preservation of health in the interests of socially significant activities, the technology is health preservation.

According to presented classification, the most productive interaction of subjects is when they have the most common object for the force application and unified position for analysis and evaluation of impact results. Authors developed a model for on-line and offline consulting, aimed at creating of productive interaction between subjects on issues of realization of those technologies in respect of which they are competent. 
The model was realized in three schools in Nizhegorodsky region for primary school. 187 primary school students and 95 families of different social status participated in the experiment. The results of the experiment are:

1). Subjects do not feel negativism during interaction with other subjects of health forming in question which they are competent due to realized technologies. More than $80 \%$ of teachers and more than $60 \%$ of parents interacted with each other willingly on the questions of children's health both in total and in its separate components.

Comparing results of current research with results of other researches we can see that presented technology and classification is in compliance with actual scientific positions $[2$, 3], that educational activity in family and in school must be must be integrated but not in all interaction's parallels, and it must not repeat alternative educational system. The authors presented several variants of interaction, though they did not review all health-forming activity's subjects and all objects involved in harmonious primary school pupils' ternary health system [10]. All these components and requirements used for authors' classification and technology development [11-13]. For example, family members, whose basic method of health-preserving environment creation is including in child's activity based on their own example, must demonstrate the same qualities, as they want to develop with their own children. These are:

- qualities, related to activity (motivation for active recreation, self-regulation, following to the rules of sports games and other sports, the ability to cooperate and healthy competition expressed in an open and honest sports competition, the application of stable objective criteria to the analysis of their activities, responsibility for fulfilling obligations to the team, spectators, fans);

- qualities, related to communication and interaction (leadership qualities, motivation for communication and interaction, desire for joint activities, identification of common interests, conflict-free discussion of conflict situations in sports, joint pain in sports, empathy)

- qualities related to the formation of a worldview (actualization of abilities, hard work, love of beauty, etc.).

Authors' technology allows to clearly identify the circle of technologies, which can be successfully used with the subject and adequately present the core of the problem and expected results of interaction between subjects during this process and rules of this interaction, following which let to remove reasons for possible conflicts and incoordination of subjects' positions.

\section{Conclusions}

1. Authors presented the foundation for classification of health-forming technologies used for primary school pupils' recovery at nowadays. Among presented there were several, that met most frequently: institutional affiliation (school, pre-school, medical, health resort etc.), subjects activity characteristics (sport, fitness, hygienic, esthetic and others), resulting component of health (motivating to healthy lifestyle, preserving, correcting), affected health components (physical rehabilitation, psychological rehabilitation, social rehabilitation), target of implementation (self-healing, co-healing, mutual healing and other). Among these foundations subjects of the impact on primary school students health were not mentioned, only their activity.

2. Authors presented health-forming technologies classification by subject of impact and by structure of interactions betwee subjects of health activity and primaty school students. Among significant subjects of this age group were:

- classmates, sport teammates, family (parents and older relatives), same generation relatives; 
- temporary children collectives (children's recreation camp, a group of friends in the local area, a community);

- pedagogical collective (physical education teacher, coach).

3. Experiment showed that each subject is object of influence on certain primary school pupil's health characteristic. Moreover, it was proved, that each of them takes part in certain type of health forming, as it shown in chart. Because of it, the influence on primary school student health has unique performance characteristics.

4. Authors developed and realized the model of interaction between subjects of healthforming activity with considering technologies' specific in order to avoid internal and external conflicts in process of primary school pupils' health-forming activity. Authors' model was implemented; its effectiveness was proven with experimental methods and mathematical statistics methods.

Further research perspectives.

The authors' classification of health-forming technologies can be adapted and transformed for other age groups, social groups and contingents. The model is built on principles of selectivity and objectification of health-forming subjects' interaction and can be remade for other groups, contingent, because it has scientific basis.

\section{Recommendations}

Health-forming classification and expected results of health-preserving subjects and their interaction types are valuable foundation for distribution of role functions between family and school representatives in developing and performing educational facility healthpreserving environment activity and also for planning and social projects on healthy lifestyle issues. The technology of health-preserving environment subjects' interaction allows representatives of primary school pupils' supplementary education to combine their child's health impact with the impact from family and school, exchange information about process and results of this activity. School administration and primary school teachers can use the information about health-forming technologies types for enriching of extracurricular activity and educational process. Health-preserving technologies researchers can use authors' technology to as a basis for experimental activity and expansion of theoretical concepts about students' harmonious health forming process. Higher education teachers and continuing professional education organizations can implement authors' classification and technology for training of specialists in health preserving.

\section{References}

1. E.A. Bashmakova, I.O. Zhdanova, Modern problems of science and education, 6 (2017)

2. G.Kh. Vakhitova, S.I. Pozdeeva, Bulletin of TSPU, 12(140), 194-196 (2013)

3. E.P. Derbeneva M.S. Belomestnykh, Experiment and innovation at school, 6, 60-65 (2014)

4. A.I. Kalosha, M.V. Rudin, Bulletin of BSU, 1, 27-32 (2015)

5. A.S. Kuznetsov, Z.M. Kuznetsova, Russian Journal of Physical Education and Sport, 14(4), 5-7 (2019)

6. A.A. Pashin, J.V. Tom, O.N. Oparina, Physical education: education, education, training, 6, 1618 (2018)

7. L.E. Tolstopovyh, L.I. Yudkina, L.I. Akinina, N.A. Sekisheva, Science and Education: Domestic and Foreign Experience Collection of Works of the Eighteenth International Scientific and Practical Conference (77-80, 2019)

8. Yu.Zh. Zhurakulova, Achievements of science and education, 15(37), 73-75 (2018).)

9. M.M. Elfimova, National Psychological Journal, 1(33), 59-67 (2019) 
10. A.L. Busygina, I.V. Archipova, T.A. Firsova, Azimuth of Scientific Research: Pedagogy and Psychology, 2(23), 351-354 (2018)

11. O.A. Kozyreva, Vestnik of Minin University, 8(2), 1 (2020)

12. I.F. Filchenkova, Vestnik of Minin University, 7(4), 3 (2019)

13. E.V. Bystritskaya, E.L. Grigoryeva, V.L. Skitnevskiy, I.A. Sedov, O.V. Reutova, A.A. Podlubnaya, L.M. Levina, Journal of Environmental Treatment Techniques, 7(3), 445-449 (2019) 